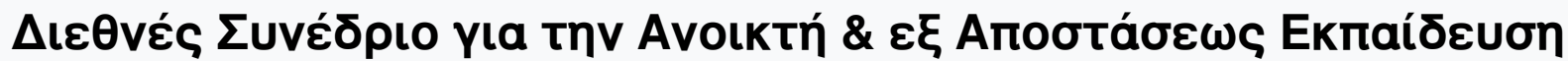

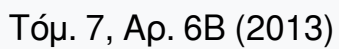

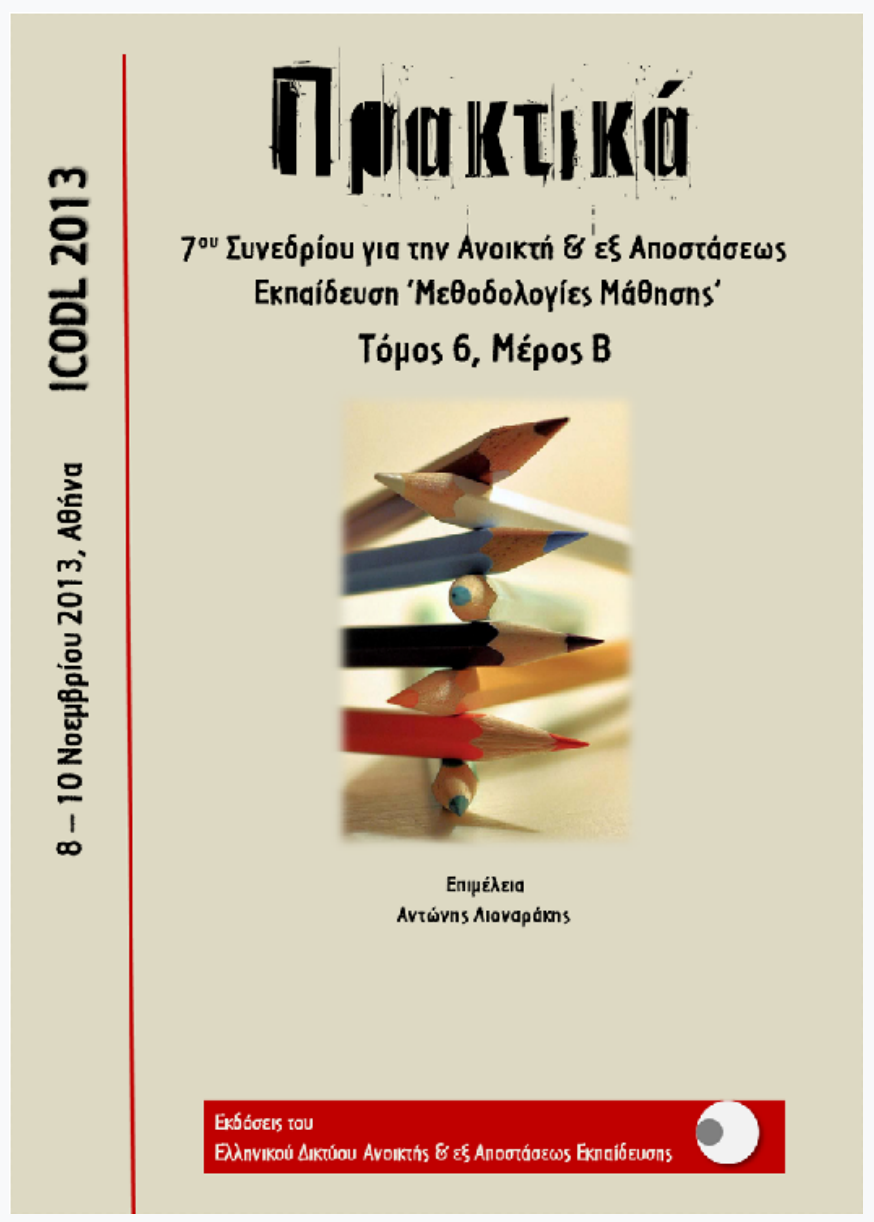

Representations of local environmental knowledge: instantiating cultural landscapes in a virtual classroom

Maria Kokolaki, Michael D. Fischer, Maria Dogkogianni

doi: $\underline{10.12681 / \text { icodl. } 597}$ 


\title{
Representations of local environmental knowledge: instantiating cultural landscapes in a virtual classroom
}

\begin{tabular}{|c|c|c|}
\hline $\begin{array}{c}\text { Maria Kokolaki } \\
\text { School of Anthropology and } \\
\text { Conservation }\end{array}$ & $\begin{array}{c}\text { Michael D. Fischer } \\
\text { School of Anthropology and } \\
\text { Conservation }\end{array}$ & $\begin{array}{c}\text { Maria Dogkogianni } \\
\text { Secondary School } \\
\text { Greek Language Teacher } \\
\text { mologogianni@gmail.com }\end{array}$ \\
$\begin{array}{c}\text { University of Kent at Canterbury } \\
\text { Honorary Research Associate } \\
\text { Institute of Educational Policy }\end{array}$ & $\begin{array}{c}\text { University of Kent at Canterbury } \\
\text { Preece }\end{array}$ & $\begin{array}{c}\text { Professor of Anthropological } \\
\text { Sciences }\end{array}$ \\
\hline m.kokolaki@kent.ac.uk & $\begin{array}{c}\text { Centre for Social Anthropology and } \\
\text { Computing (U.K.C.) } \\
\text { Director }\end{array}$ & \\
\hline & m.d.fischer@kent.ac.uk & \\
\hline
\end{tabular}

\begin{abstract}
In the modern world new technologies have fostered a new sense of community and sense of time and place that put emphasis on global connectedness while at the same time enhancing local distinctiveness. In this outline a proposed project that leverages virtual online communities pedagogically to elicit, represent and promote a local sense of place and environmental knowledge in secondary Greek schools, in the context of changes in the analytical curricula where environmental education and local history become independent subjects.

Specifically, we propose a project based on team work and supported by exploitation of Web 2.0 technology in the History Class of third grade junior high school in an interdisciplinary approach with other fields such as Modern Greek Language, Literature and Art. This is based on a constructivist approach, and aims to promote an interest in environmental issues relating to specific locales and the strengthening of bonds with the local cultural and environmental legacy. We further aim to increase awareness in children of the multiple approaches and representations of both the environment and their locale and an understanding of the potential of those approaches.
\end{abstract}

Keywords: On-line learning communities, Local environmental knowledge, Sense of place

\section{Introduction.}

Themes of place and local knowledge are very important for environmental education. The connection of people with places acquires new meaning in present times, where the sense of place is rapidly being displaced and altered by new technologies (Malpas, 2008). At the same time these new technologies attribute increased significance and value to places through 'opening up' places to a world net-based audience and by enhancing the specific and unique character of each locale through provision of direct comparators.

Accordingly, Sahlins (1999) notes a contemporary paradox in that "localization develops apace with globalization, differentiation with integration; that just when the 
forms of life around the world are becoming homogeneous, the peoples are asserting their cultural distinctiveness" (Sahlins, 1999: 410).

We focus on developing effective learning about environmental issues related to the local knowledge and sense of place, proposing an interdisciplinary approach to Greek secondary education with the aid of web-based transformative and dynamic environments.

This proposal draws on social constructivist principles using ethnographic methods of participant observation, documentation and interviews to build awareness of local environmental changes and their representation in a local discourse. This interaction will help students to identify and illuminate changes in the landscape and place-based local environmental perceptions. Further this approach aims not only at developing understanding of local collective constructions of knowledge but also at encouraging positive action for the conservation of local knowledge and the local views of place and landscape. The goal is to develop a greater capacity for environmental agency on the part of students by increasing both an awareness of options available to them, and the skills and knowledge needed to convert these options into genuine choices that can form the basis of an environmentally aware action.

Environmental secondary education in Greece is done on a voluntary basis and the related programs are not carried out in the formal school curriculum. These are rather incorporated into other non-formal types of school fostered educational activities. However, ecological consciousness is a value that runs through the analytical curricula of many subjects which gives educators an opportunity to build environmentally orientated projects on an interdisciplinary basis. Additionally, in the new analytical curricula piloted in secondary education the subjects "Environment and education on sustainable development" and "Local History," form part of a proposed "zone of experiential activities". Although "Local history" has been a part of the analytical curricula since 2003, in the new curricula this is linked in part to environmental education.

\section{Theoretical concepts}

a. Sense of Place

"Human activity in space is localized" according to Soja (1971: 3), as human activity is related to a certain locale which holds its own frame of idiosynchratic characteristics. This aspect of human nature reveals the complex link between people and their natural environment within which variables related to a given locale such as climate, land, or economy influence human activity and shape human interaction.

In this perspective, people are connected to the locale they inhabit and establish an identity "with pieces of geographical space" (Soja, 1971: 3). They further develop attitudes, perceptions and feelings concerning their locale, which comprises natural resources, microclimate, plant and animal world. So their sense of place can be interpreted within a context of emotional ties or feelings. Malpas finds that sense of place refers:

"...both to a sense of the character or identity that belongs to certain places or locales and to a sense of our own identity as shaped in relation to those places, such that we might even be said to belong to those places." (Malpas, 2008: 201)

This spatial identity for many researchers has multiple aspects, such as place attachment or place belonging or place meaning (Kudryavtsev et al., 2012). 
Moreover, the interpretation of space varies greatly from the perspectives of a great range of disciplines such as geography, psychology, history, and so on.

So, there is a bond between society and the geographical space in which the former is located, which sustains a fundamental political element in the organization of space and, more importantly, is a major factor governing human interactions in space, resulting in a so-called human spatial or territorial identity.

Accordingly, Dear and Wolch (1989: 7) state that: "Any locale is, at once a complex synthesis of objects, patterns, and processes derived from the simultaneous interaction of 'different levels of social process', operating at varying geographical scales and chronological stages."

Finally, Scazzosi (2004) uses the term 'landscape' in order to cover a wide range of meanings from natural, environmental, visual and aesthetic to historic and sociocultural. As she notices, landscapes or places are currently seen as archives with "material and immaterial traces of the history of men and nature" (Scazzosi, 2004: 339) that permits us to build on our future. These carry traces of the past as 'palimpsest' documents that provide an opportunity to read and acknowledge "modes of life and work, agricultural techniques and construction materials, land uses, festivals and the symbolism of various elements, but also of climate, vegetation and habitat" (Scazzosi, 2004: 339). In this sense a cultural landscape denotes the interdependence between nature and humanity.

\section{b. Traditional Environmental Knowledge}

"Indigenous", "local" or "traditional" knowledge are terms that are often used interchangeably to describe the knowledge of local people regarding their locale (Fischer, 2005: 738). Bicker et al. (2004: xii) focuses on the dynamism of local knowledge, Fischer (2005) introduces the term "powerful knowledge", as a bridge between ideation and practice. Anteweiler proposes that:

Indigenous or local knowledge is both universal and specific and defies any simple essentialism. Local knowledge is neither indigenous wisdom nor simply a form of science, but a locally situated form of knowledge and performance found in all societies. It comprises skills and acquired intelligence responding to constantly changing social and natural environments (Antweiler, 2004: 1).

In particular, traditional ecological/environmental knowledge (TEK) is used specifically to describe a peoples' knowledge of local environmental resources. Following Heckler (2008: 2) TEK is viewed as dynamic "emerging from ecopolitical discourse, practical engagement with the landscape and social relationships". It also refers to processes of interaction, transmission and change/innovation (Heckler, 2008: $5)$.

TEK supports environmentally sustainable communities, not by static conformance to tradition, or avoiding use of natural resources, but by active environmental agency. Environmental agency is developed through individuals being aware of the options available (material), turn a subset of these into available choices by learning and practice (culture), and exercising these choices in a manner that is sustainable (critical). This allows for progression, change and controlled transformation of the locale without remaining locked into the past. 


\section{c. Environmental Literacy and Multi-literacies}

Following Stables (1998), we use a threefold conception of environmental literacies (Stables 1998): functional, cultural and critical environmental literacies. School can be an integral platform for learning and applying these to ongoing development of an eco-cultural present.

Functional environmental literacy involves understanding of the materials and processes of nature, ecosystems and local environmental issues and how those operate. Cultural environmental literacy implies knowledge of cultural values associated with the environment and involves semiotic interaction between society and its environment. Critical environmental literacy relates to engagement with and action taken on environmental issues (Stables, 1998; Bishop et al, 2010).

Knowledge of environmental issues and consequences, developing local environmental knowledge, and critical, active, attitudes towards the environment lie in the core of environmental education.

Harness and Drossman (2011) observe that cognitive and social constructivist motivated pedagogies are based on active participation, recognition of the social nature of learning, self-regulated learning, authentic learning situations, while also eliciting prior knowledge, creating cognitive dissonance; applying new knowledge with feedback and reflecting on learning.

Further, taking into account the emergence of new technologies and multiplicity of new media and the tension between increasing local diversity and global connectedness, (Cazden et al., 1996), these multiliteracies underlie a pedagogical framework for considering multiplicity of representations within a variety of texts (print, digital, aural and visual).

\section{d. Online learning communities and socio-constructivist theories of learning}

Rosen and Nelson (2008: 220) use the term Education 2.0 to denote "the use of digital tools to transform teaching and learning by having learners, as well as teachers, participate in knowledge creation and interactively build distributed communities, or networks, of learning".

Online learning communities can leverage aspects of student networking to transform individual-focused pedagogy into collaborative learning, while refocusing learning environments from teacher-centric to student-participatory (Rosen \& Nelson, 2008). These enable students to set and achieve objectives and construct knowledge in a collaborative and playful manner.

Social Web 2.0 tools, and online communities in particular, are consistent with constructivist and social constructivist pedagogy, encouraging students to take initiatives and actively construct, not just receive, knowledge. From a social constructivist perspective this results from social interaction, which is promoted by Web 2.0 collaborative environments (Wang, 2009; Rosen \& Nelson, 2008). Wikis support student-led communication, participation, reading and writing multimodal texts, commenting and being commented upon, while also reflecting on their work using discussion or commenting features (related to metacognition). The discussion and comment sections facilitate teachers in providing feedback to students, while the 'history' tool allows them to watch and assess the progress of the students (Rosen and Nelson, 2008). 
Commonality, interdependency and situatedness are aspects of learning in the sense of Vygotskian situated cognition (Hung \& Der-Thanq, 2001). Web-based learning communities not only promote this type of interaction and collaboration but also introduce a new sense of situatedness both in time and space, which transforms and expands placement and synchronicity of cognitive processes. Further, it seems that identity formation is promoted in both a collective and individual sense.

\section{Project Design - Eliciting sense of place}

We are basing the project on the hypothesis that landscapes are 'living' archives (Scazzosi, 2004: 339), continuously transforming to promote an ever changing sense and experience of space by the local community. This is an outcome of the transformational shift of modernity and globalization which is conveyed in multiple ways. In this sense shared environmental knowledge is adapting to spatial transformation and global translocation of experience, entangled not just in the present circumstances, but the past as well.

So, the main objectives of this project are to identify and represent landscape development and transformation and to analyse further the impact of these changes on socio-cultural perceptions about the landscape especially in places that have changed significantly in the last decades for a variety of reasons. The project will be carried out by students as a part of an experiential, collaborative and social constructivist approach.

The project will help students experience local landscape, explore and reveal the ways in which environmental knowledge is instantiated in a local sense of place and how this adapts to new situations that have and are emerging. As a part of the social constructivist approach we promote an interest in environmental issues related to specific locales and the strengthening of bonds with the local cultural and environmental legacy. We also focus on bringing children in touch with issues emerging from multiple approaches, viewpoints and representations and at revealing the potential of those approaches; the options that these represent and the knowledge and skills needed to transform these into choices.

The project is based on ethnographic methods that use participation and observation and build on experience and on the use of new technologies that ensure the interdependency, both as a community of peer/learners and integrally between students and their environment. These methods are based on team work and will be supported by exploitation of web 2.0 technology in the History Class of the third grade junior high school as an interdisciplinary approach to other fields like Modern Greek Language, Literature and Art. New technologies facilitate the creation of a variable virtual space/time with the objective to articulate and embed local discourse about physical, social and cultural within present and past space/time contexts. This online learning community, created using a wiki, will provide a useful tool for sustaining local knowledge in the framework of the pedagogies of multiliteracies where "all forms of representation, including language, should be regarded as dynamic processes of transformation rather than processes of reproduction" (Cope \& Kalantzis, 2009: 175).

The wiki environment will support this project by being flexible and promoting collaboration so that the students not only are encouraged to produce texts of various styles (including new media-multimodal texts) about local environmental issues, but they are also supported in their teamwork and evaluation of each others' work. The 
wiki supports students with the opportunity to work in small groups (of four or five), while encouraging them to express personal opinions and reflections when writing in the 'comments' section and collective conclusions and evaluations.

Further the virtual learning community encourages active participation in authentic learning situations by creating and resolving authentic problems, helps learners apply their prior knowledge and provides constant feedback in order for the new knowledge to be constructed, shared, and reviewed or reflected on.

As far as the students' ethnographic research is concerned, it will initially focus on current or historical environmental problems and change. Students learn how to search in archives and utilize web information to elicit information about multiple transformations in the local community. Field research follows, which might include individual and group interviewing, eliciting life-histories, learning how to keep diaries and notes, take photos and use digital cameras and voice recorders, based on common mobile phones where possible, as well as in other forms such as drawings. Moreover, students will learn how to transcribe experience into field notes and how to produce texts and representations of their gained insights into their own cultural and natural surroundings. These can take the form of texts, photo essays, poems, songs, short films and even group productions such as plays and other forms of drama.

In parallel, the use of internet resources and general purpose software like Word, Powerpoint and Moviemaker supports students in the opportunity not only to become familiar with new technologies, but also to create useful outcomes in a playful and enjoyable way that they can transfer to other contexts. Students learn how to use a variety of narrative techniques and to construct multilevel flexible texts using multifarious tools, like sounds and pictures, in order to produce their own version of reality and address modern problems like environmental change caused by human intervention or by climate change.

Finally children will be given the opportunity to compile and create their own stories of the place in a persistent digital form by combining their experience and their new acquired knowledge and using technology for producing multimodal texts (literary and medial). Moreover children in the wiki environment can navigate into their own observations, reflect and find traces of their identities in their texts. In this way, students potentially re-construct and re-invent local traditional knowledge, while transforming it for contemporary purposes becoming environmentally literate in the most active sense.

\section{Conclusions - Implications for the future}

Giaccardi and Polen (2008: 283) hold that "Bringing or strengthening a sense of place - and therefore, a living and sustainable relationship with heritage-means creating communication and interaction spaces capable of sustaining a community's engagement with the physical and social settings of the heritage".

Modern environmental problems, caused either by human intervention or attributed to natural causes, usually result in transformations of landscapes and of human response to this change. The issue of environmental change and human adaptation to it, includes a wide range of perceptions of value. It is critical that children (and adults) take greater ownership of outcomes and adapt not only through conformance to change, but by initiating change as well. The development of environmental agency, particularly in the context of the local, can greatly impact and moderate how a community adapts to circumstances and change. 
In the framework of a socio-constructivist approach, the project leverages the construction and empowerment of local cultural heritage, and in particular landscape experience and sense of place, by bringing together the learners' community with their environment in the physical and sociocultural dimension. Local environmental knowledge is approached, elicited, de-codified, discussed and finally codified and instantiated in virtual representations by the students. The procedure includes field research methods as part of an experiential approach aided by technology in order to elicit, organize and assess data.

The development of a web-based learning community as an educational medium not only supports projecting ecological representations of local landscapes but also in capturing local perceptions and representations that may reveal the interdependence of humans and culture with nature and identify the degree of human responsibility and the consequences of human action. So the project is orientated to the effect human action bears on local sites and aims at enhancing awareness concerning cultural landscapes and enhancing their environmental agency.

School-based formal learning will interweave with the local community and develop forms of non-typical and atypical learning. As a result, this new form of eliciting and constructing knowledge enhances both students' and the community's awareness of the environment. So the project promotes the new type of space/time situatedness that local web platforms (wikis) introduce, using virtual tools in order to create an actual yet imaginary locus where knowledge and experience are exchanged, shared and translocated while practices such as online research or giving feedback and participating in discussions take place.

Moreover, this could be an alternative and innovative way to help local integration and to reflect on the issue of landscape transformation, which is of high significance for many communities experiencing multiple or abrupt and wide range changes for a number of reasons, as is the specific community which we chose for piloting this project. Finally, this project could be utilized in the framework not only in the current curricula in Greek secondary education but also of those that put particular emphasis on local history and environmental education

\section{References}

Anteweiler, C. (2004). Local Knowledge, Theory and Methods: An Urban Model from Indonesia. In Bicker, A., Sillitoe, P., \& Pottier, J. (Eds), Investigating Local Knowledge: New Directions, New Approaches, (pp. 1-34). Aldershot: Ashgate Publishing.

Bicker, A., Sillitoe, P., \& Pottier, J. (2004). Preface. In A. Bicker, P. Sillitoe, \& J. Pottier (Eds), Investigating Local Knowledge: New Directions, New Approaches, (pp. xi-xii). Aldershot: Ashgate Publishing.

Bishop K., Reid A., Stables A., Lencastre M., Stoer S., \& Soetaert R. (2000). Developing Environmental Awareness through Literature and Media Education: Curriculum Development in the Context of Teachers' Practice. Canadian Journal of Environmental Education, 5, 268286.

Cazden C., Cope B., Fairclough N., Gee B. et al. (1996). A Pedagogy of Multiliteracies. Designing Social Futures. Harvard Educational Review, 66(1), 60-92.

Cope B., \& Kalantzis M. (2009). Multiliteracies: New Literacies, New Learning. Pedagogies: An International Journal, 4, 3, 164-195.

Dear, M. and Wolch, J. (1989). How territory shapes social life, in J. Wolch and M. Dear (Eds), The Power of Geography, (pp. 3-18). London \& Boston: Unwin Hyman.

Fischer, M. D. (2005). Culture and Indigenous Knowledge Systems: Emergent Order and the Internal Regulation of Shared Symbolic Systems. Cybernetics and Systems, 36, 735-752. 
Harness H. \& Drossman H. (2011). The environmental education through filmmaking project. Environmental Education Research, 17(6), 829-849.

Heckler, S. (2008), Introduction, in S. Heckler (Ed.) Landscape, Process and Power: Re-evaluating Traditional Environmental Knowledge, (pp. 1-18). New York, Oxford: Berghahn Books

Hung, D. W. L. \& Der-Thanq, C. (2001). Situated cognition, Vygotskian thought and learning from the communities of practice perspective: Implications for the design of web-based e-learning. Educational Media International, 38, 3-12.

Giaccardi E. \& Palen L. (2008). The Social Production of Heritage through Cross-media Interaction: Making Place for Place-making. International Journal of Heritage Studies, 14(3), 281-297.

Malpas J. (2008). New Media, Cultural Heritage and the Sense of Place: Mapping the Conceptual Ground, International. Journal of Heritage Studies, 14(3), 197-209.

McCarthey S. J. (2012). Understanding ecologies of writing in multiple settings", Pedagogies: An International Journal, 7(3), 261-267.

Kudryavtsev A, Stedman R.C. \& Krasny M.E. (2012). Sense of place in environmental education. Environmental Education Research, 18(2), 229-250.

Rosen D., \& Nelson Ch. (2008). Web 2.0: A New Generation of Learners and Education. Computers in the Schools, 25(3-4), 211-225

Sahlins, M. (1999). Two or Three Things that I Know about Culture, Journal of the Royal Anthropological Institute (n.s.) 5(3), 399-421.

Soja, E. W. (1971). The Political organization of Space. Commission on College Geography, Resource Paper No. 8, Washington: Association of American Geographers.

Scazzosi L. (2004). Reading and assessing the landscape as cultural and historical heritage. Landscape Research, 29(4), 335-355.

Stables A. (1998). Environmental Literacy: functional, cultural, critical. The case of the SCAA guidelines. Environmental Education Research, 4(2), 155-164.

Wang Q. (2009). Designing a web-based constructivist learning environment. Interactive Learning Environments, 17(1), 1-13. 